\title{
Effective small interfering RNA delivery in vitro via a new stearylated cationic peptide
}

\author{
This article was published in the following Dove Press journal: \\ International Journal of Nanomedicine \\ 2 May 2015 \\ Number of times this article has been viewed
}

\author{
Baoling Chen ${ }^{1,2}$ \\ Ran Pan',2 \\ Diana Askhatova' \\ P Chen ${ }^{1,2}$ \\ 'Department of Chemical \\ Engineering, ${ }^{2}$ Waterloo Institute \\ for Nanotechnology, University \\ of Waterloo, Waterloo, ON, Canada
}

Correspondence: P Chen

Department of Chemical Engineering, University of Waterloo, 200 University Avenue West, Waterloo, ON N2L 3GI, Canada

Tel +I 5 I 98884567 ext 35586

Fax + I 5198884347

Email p4chen@uwaterloo.ca

\begin{abstract}
A crucial bottleneck in RNA interference-based gene therapy is the lack of safe and efficient delivery systems. Here, a novel small interfering RNA (siRNA) delivery peptide, STR-HK, was constructed by conjugating a stearyl end to the N-terminus of the peptide sequence HHHPKPKRKV, where PKPKRKV is an altered sequence of the nucleus localization signal (PKKKRKV) and contributes to the cytosol localization of STR-HK-siRNA complexes. Histidine is a linker and plays an important role in disrupting the endosomal membrane via the proton sponge effect. As expected, STR-HK formed complexes with siRNA with a particle size of 80-160 nm in diameter and efficiently delivered Cy3-labeled glyceraldehyde 3-phosphate dehydrogenase siRNA into PC-3 human prostate cancer cells. The transfection efficiency of STR-HK at molar ratio of 60/1 was comparable to that of Lipofectamine 2000, one of the most efficient commercially available transfection reagents. Furthermore, the STR-HK-siRNA complexes exhibited minimal cytotoxicity, which was significantly lower than that of Lipofectamine. Taken together, the strategy of conjugating the stearyl moiety with HHHPKPKRKV as a non-viral siRNA delivery system is advantageous.
\end{abstract}

Keywords: RNA interference, cellular uptake, cytotoxicity, gene silencing, physicochemical characterization

\section{Introduction}

RNA interference is a specific cellular post-transcriptional gene silencing mechanism, which can be induced by evocation of enzymatic degradation of a corresponding mRNA. Double-stranded small interfering RNA (siRNA) consisting of 21-25 nucleotides plays an important role in this process. siRNA can be synthesized exogenously and delivered to the cytoplasm to be loaded into the RNA-induced silencing complex (RISC). RISC induces the siRNA to unwind in a strand-specific manner. The sense strand of siRNA is cleaved and removed, and then the remaining antisense strand of the duplex acts as a guide to lead the RISC complex into the complementary sequence of the target mRNA. Upon association of the target mRNA with RISC, AGO protein cleaves the mRNA and interrupts the translation process. ${ }^{1-3}$ This being a potent and highly specific therapeutic strategy, siRNAs have been evaluated as potential therapeutic agents for a wide range of gene-based diseases. However, the major limitations for the use of siRNA are the instability of naked siRNA in physiological conditions, the nature of negative charge, and hydrophilicity. Currently, various strategies have been applied to improve siRNA's nuclease resistance without interfering with its silencing efficiency, ${ }^{4,5}$ such as chemical modifications in the nucleobases, the phosphate ester backbone, and conjugation with hydrophobic functional groups. ${ }^{6}$ However, this is very time consuming and costly. Carrier-based strategies have been explored as a simple and fast means to protect the siRNA and maximize its therapeutic effects. 
A number of delivery carriers have been developed and characterized, including peptides, ${ }^{7}$ polymers,,${ }^{8,9}$ liposomes, ${ }^{10,11}$ lipids, ${ }^{12,13}$ and viral vectors. ${ }^{14}$ Due to the fundamental drawbacks of viral vectors, such as toxicity and immunogenicity, non-viral vectors have served as an alternative because of their advantage in inducing relatively low toxicity and nearly no immune response. ${ }^{1,2}$ Among these non-viral vectors, cell-penetrating peptides (CPPs) are being increasingly utilized for gene delivery. ${ }^{3,15,16}$ Researchers have proven that CPP MPG, the peptide derived from both the fusion peptide domain of HIV-1 gp41 protein and the nuclear localization sequence (NLS) - PKKKRKV - of SV40, can deliver DNA into the nucleus efficiently. NLS plays an essential role in importing DNA into the nucleus. ${ }^{17}$ A single mutation of a lysine residue to a proline residue (PKPKRKV) in NLS limits its nuclear translocation but enhances release of the cargo into the cytoplasm, which is helpful for siRNA intracellular localization. ${ }^{18}$ Recently, stearylation has proven to be successful in increasing the transfection efficiency of CPPs for DNA delivery ${ }^{19-25}$ or that of polyethyleneimine for siRNA delivery. ${ }^{26}$ The increased transfection efficiency is attributed to the enhanced compaction of DNA, increased endosomal escape, and higher cellular uptake, which are all conferred by the stearyl moiety.

Having considered the similarity of siRNA and DNA, a novel type of non-viral siRNA delivery vector was constructed by introducing a stearyl moiety to the N-terminus of the sequence. Three histidine residues serve as a linker between the stearyl moiety and PKPKRKV. The other reason for using histidine is that it will be helpful for the rapid release of siRNA into the cytosol after intracellular uptake. In this report, the physicochemical and biological characteristics of this new peptide, STR-HK $\left(\mathrm{C}_{18}-\mathrm{HHHPKPKRKV- \textrm {NH } _ { 2 }}\right)$, were investigated in order to evaluate its potential for siRNA delivery.

\section{Materials and methods \\ Materials}

Peptide STR-HK $\left(\mathrm{C}_{18}\right.$-HHHPKPKRKV-NH $\left.{ }_{2}\right)$ with a molecular weight of $1500.9 \mathrm{~g} / \mathrm{mol}$ was synthesized by CanPeptide Inc. (Quebec, QC, Canada) with a purity $>95 \%$. The highperformance liquid chromatography and liquid chromatography-mass spectrometry characterization of STR-HK is shown in Figures 1 and 2. siRNA targeting the glyceraldehyde 3-phosphate dehydrogenase (GAPDH) gene and Cy3-labeled GAPDH siRNA were purchased from Ambion (SilencerTM GAPDH siRNA kit). The siRNA targeting eGFP gene, GCGACGUAAACGGCCACAAGU, was purchased from Dharmacon, whose antisense sequence is ACUUGUGGCCGUUUACGUCGC and sense sequence is GACGUAAACGGCCACAAGUUC. The negative control siRNA was purchased from Ambion. Cell counting

Auto-scaled chromatogram

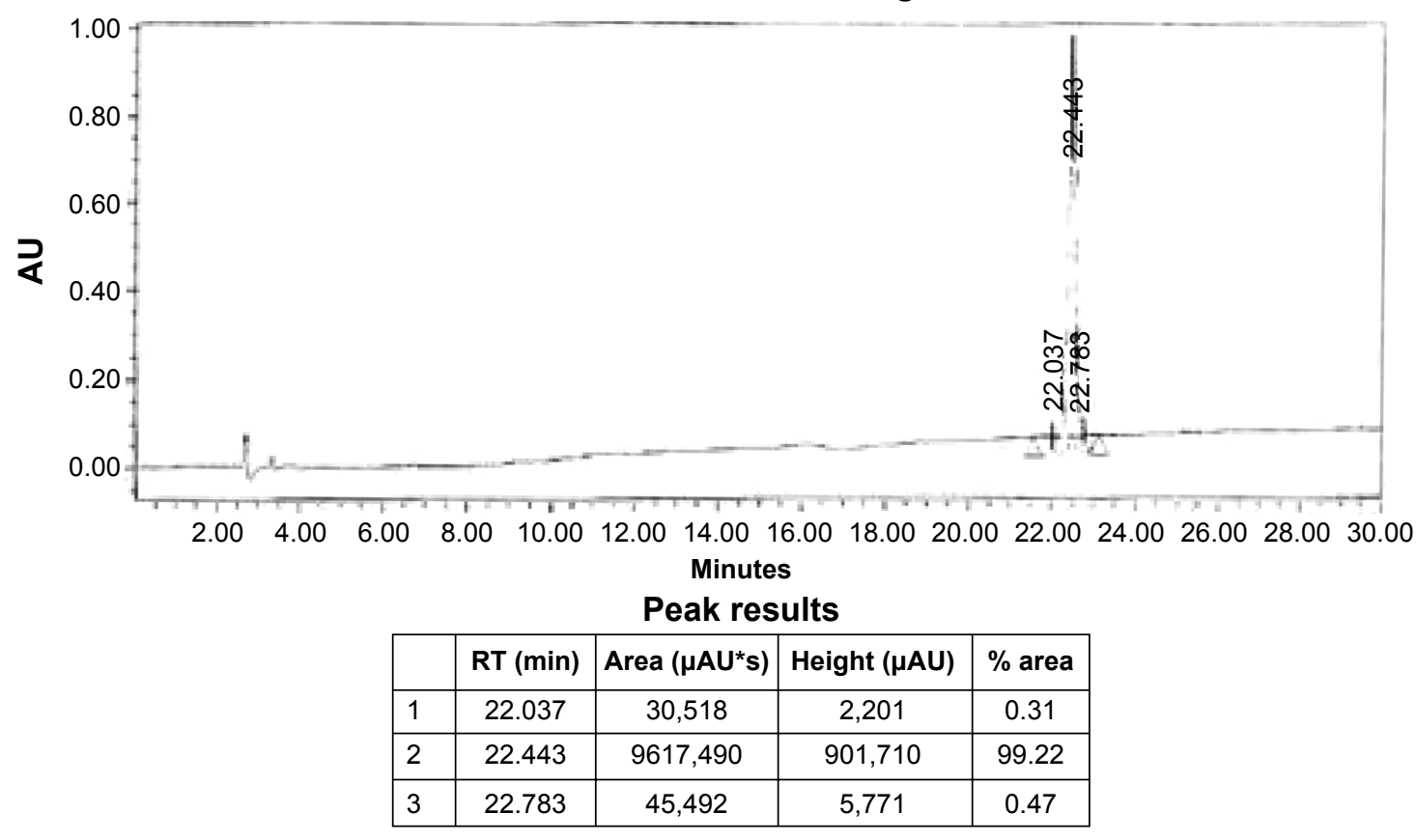

Figure I High-performance liquid chromatography data of STR-HK.

Abbreviations: $\mathrm{AU}$, absorbance unit; min, minutes; $\mathrm{RT}$, retention time; s, seconds. 


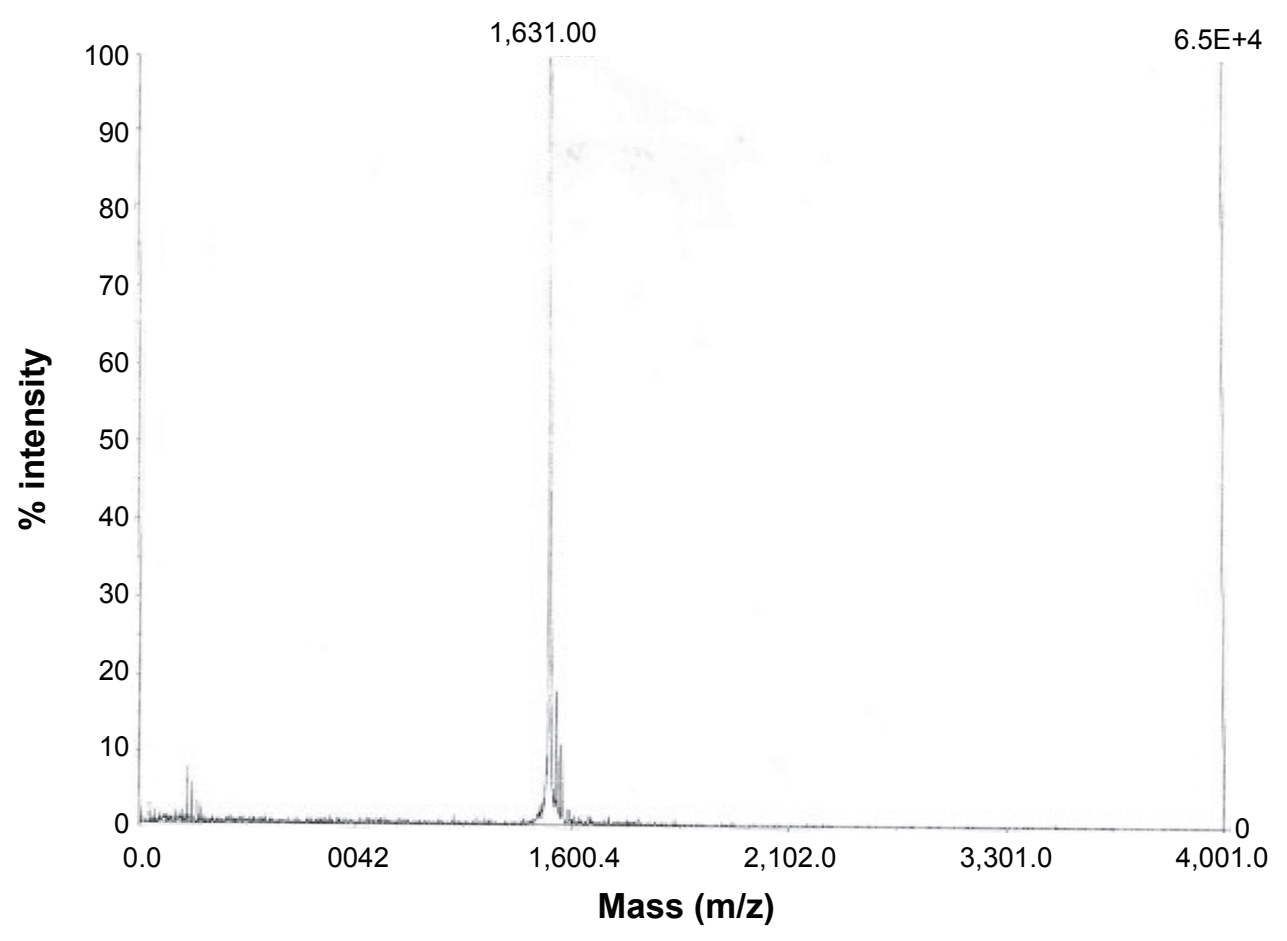

Figure 2 Liquid chromatography-mass spectrometry data of STR-HK.

kit-8 (CCK-8) was used for cell viability test and was purchased from Dojindo Molecular Technologies.

\section{Cell culture}

Human prostate cancer cell line (PC-3) was purchased from the American Type Culture Collection. PC-3 cells were grown in F-12K medium (Thermo Scientific, Ottawa, BC, CA) supplemented with $10 \%$ fetal bovine serum (SigmaAldrich Co., St Louis, MO, USA). The cell line was cultured at $37^{\circ} \mathrm{C}$ in a $5 \% \mathrm{CO}_{2}$ atmosphere.

\section{Preparation of STR-HK-siRNA complexes}

For the cell treatments, siRNAs were mixed with peptides at various molar ratios (peptide/siRNA), and siRNA concentration was $100 \mathrm{nM}$. For the cell treatments, the peptide/siRNA complexes were prepared in Opti-MEM (Thermo Fisher Scientific, Waltham, MA, USA). For the physicochemical characterization, the complexes were prepared in RNase-free water. The complexes were incubated at room temperature for 20 minutes. All complexes were used immediately after their preparation.

\section{Agarose gel-shift assay}

STR-HK-siRNA complexes at a peptide/siRNA molar ratio ranging from $1 / 1$ to $80 / 1$ were prepared in RNase-free water at the room temperature for 20 minutes. siRNA alone was used as a control. Each well contains $300 \mathrm{ng}$ of siRNA. The samples were analyzed by electrophoresis in agarose gel $(1.2 \% \mathrm{wt} / \mathrm{vol})$ stained with ethidium bromide.

\section{Isothermal titration calorimetry}

siRNA condensation was evaluated using isothermal titration calorimetry (ITC). The experiments were conducted using a Nano-ITC calorimeter (TA Instruments, New Castle, DE, USA). A $500 \mu \mathrm{M}$ STR-HK peptide solution and a $10 \mu \mathrm{M}$ siRNA solution were both prepared in RNase-free water. All the samples were degassed in a degassing station (TA Instruments) prior to the experiments. RNase-free water was placed in the ITC reference cell. For each titration, $2 \mu \mathrm{L}$ of the peptide solution in a pipette rotating at $250 \mathrm{rpm}$ was injected into the siRNA solution in the sample cell of the calorimeter, which was equilibrated to $25^{\circ} \mathrm{C}$, with an interval of 300 seconds between injections. The heat of dilution was measured by titrating the STR-HK solution into RNase-free water and was later subtracted from the sample measurement. The data were analyzed using NanoAnalyze software v.2.3.0.

\section{Particle size and zeta potential}

The peptide-siRNA complexes were prepared at molar ratios from 10/1 to 60/1 with a fixed siRNA concentration of $100 \mathrm{nM}$, as described above. Particle size measurements 
were performed at $25^{\circ} \mathrm{C}$ in transparent ZEN0040-disposable micro cuvette cells $(40 \mu \mathrm{L})$ using a Zetasizer Nano ZS (Malvern, UK). The zeta potentials were measured using a clear DTS1070-zeta dip cell.

\section{Scanning electron microscopy}

The morphology of STR-HK-siRNA complexes at a molar ratio of 20/1 was observed by scanning electron microscopy (SEM). The peptide-siRNA complexes were prepared as described in the Preparation of STR-HK-siRNA complexes section. The SEM samples were prepared by dropping the peptide-siRNA complexes onto a substrate to air dry at room temperature and then coated with $10 \mathrm{~nm}$-thick gold before measurement.

\section{Transmission electron microscopy}

Transmission electron microscopy (TEM) was utilized to acquire the morphology of STR-HK-siRNA complexes at molar ratio of 20/1 with siRNA concentration of $100 \mathrm{nM}$. Ten microliters of the samples was applied to a 400 mesh Formva-coated copper grid (Canemco and Marivac, Canton de Gore, QC, Canada) for 3-5 minutes. The sample was then washed five times with RNase-free water and dried over night. Uranyl acetate (Electron Microscopy Sciences, Hatfield, PA, USA) was used to stain the samples. An electron micrograph of the STR-HK-siRNA complexes was acquired using TEM (Philips CM-10 TEM; Philips, the Netherlands).

\section{Circular dichroism spectroscopy}

Circular dichroism was used to investigate the secondary structure of the peptide and its change after forming a complex with siRNA. Spectra at 250-190 nm with a spectral resolution and pitch of $1 \mathrm{~nm}$ and scan speed of $200 \mathrm{~nm} /$ minute were recorded using a J-810 spectropolarimeter (Jasco, USA). Increasing amounts of siRNA were added to the peptide, which was at a fixed concentration of $30 \mu \mathrm{M}$, to obtain different molar ratios. The samples were transferred into $1 \mathrm{~mm}$ long quartz cells and maintained at $25^{\circ} \mathrm{C}$. The spectra presented here were the average of three measurements.

\section{Cytotoxicity}

The cytotoxicity of peptide-siRNA complexes was determined by the CCK-8 assay. In brief, cells were seeded at 10,000 cells/well in clear, flat-bottomed, 96-well plates (Costar) 24 hours before treatment. After being washed, $100 \mu \mathrm{L}$ of Opti-MEM that contained peptide-siRNA complexes at different molar ratios was added to the wells and incubated for 4 hours. Thereafter, $50 \mu \mathrm{L}$ of $30 \%$ serum containing medium was added, and the cytotoxicity of the relevant reagents was determined by the CCK- 8 assay after 24 hours and 48 hours. Then, the cultures were removed from the incubator, and the absorbance at $570 \mathrm{~nm}$ was read on a plate reader (FLUOstar OPTIMA; BMG, Germany). The background absorbance of the multiwell plates at $690 \mathrm{~nm}$ was determined and subtracted from the $570 \mathrm{~nm}$ measurement. The results obtained from triplicate wells were averaged and normalized to the value obtained from the non-treated cells.

\section{Cellular uptake}

PC-3 cells $(80,000 /$ well) were cultured in a 24-well plate for 24 hours before treatment. The cells were incubated with STRHK-Cy3-labeled GAPDH siRNA complexes at a molar ratio of 40/1 for 4 hours. Lipofectamine 2000 (Lipo)-Cy3-labeled GAPDH siRNA complexes were used as a positive control here. Thereafter, the cells were washed three times with PBS and then fixed by $4 \%$ paraformaldehyde. The nucleus of the cell was stained by 4',6-diamidino-2-phenylindole (DAPI). Images were taken with a fluorescence microscope. To quantify the cellular uptake of peptide-siRNA complexes, PC-3 cells $(80,000 /$ well) were cultured in 24 -well plates 24 hours before treatment. The cells were incubated with peptide-Cy3labeled GAPDH siRNA complexes at different molar ratios for 4 hours. Next, cells were rinsed with PBS and then washed with heparin $(10 \mathrm{U} / \mathrm{mL})$. After thorough washing, trypsinEDTA was added to detach the cells from the plate. The cells were resuspended in 4\% paraformaldehyde for analysis using fluorescence activated cell sorting (BD FACSVantage SE Cell Sorter; BD Biosciences, CA, USA).

\section{In vitro transfection}

PC-3 cells were seeded at 80,000 cells/well in 24-well plates 24 hours before treatment. Cells were treated with peptidesiRNA complexes in $300 \mu \mathrm{L}$ of Opti-MEM at different molar ratios for 4 hours. Thereafter, $300 \mu \mathrm{L}$ medium containing $20 \%$ fetal bovine serum was added to each well. After incubation of 48 hours, cells were washed and collected for quantitative real-time polymerase chain reaction (PCR) analysis.

First, the total RNA was extracted from the treated cells using the SV Total RNA Isolation System (Promega Corporation, Fitchburg, WI, USA). A NanoDrop (NanoDrop spectrophotometer ND-1000; Thermo Scientific) was used to determine the RNA concentrations. The RNA samples were reverse transcribed into cDNA using a Bio-Rad iScript cDNA synthesis kit according to the manufacturer's protocol. After the cDNA was synthesized, PCR was performed with Brilliant II Fast SYBR Green QPCR Master Mix 
(Agilent Technologies, Santa Clara, CA, USA) using an Mx3005PтM Real-Time PCR System (Agilent Technologies). The sequences of the primers used for the human GAPDH gene were 5'-GAAATCCCATCACCATCTTCCAG-3' and 5'-GAGCCCCAGCCTTCTCCATG-3' (Sigma-Aldrich). Cyclophilin, a housekeeping gene, was used as an internal control to normalize the GAPDH gene expression. Human cyclophilin mRNA was amplified using the following primers: 5'-GGTGATCTTTGGTCTCTTCGG-3' and 5'-TATATGCTCTTTCCTCCTGTG-3' (Sigma-Aldrich).

\section{Statistical analysis}

Results were expressed as mean values \pm SD. Data were analyzed by two-tailed $t$-test, and only $P$-values $<0.05$ were considered statistically significant.

\section{Results}

\section{Characterization of peptide-siRNA complexes}

Agarose gel-shift assay was applied to detect the loading capacity of STR-HK. Basic amino acids, such as arginine and lysine, were protonated and able to interact with the negatively charged phosphate groups on siRNA sugar rings through electrostatic interactions. STR-HK contains four positively charged residues: three arginine and one lysine so as to strongly interact with siRNA. In the agarose gel electrophoresis experiment, when voltage is applied, free siRNA will move toward the positive electrode. As shown in Figure 3, the band produced at higher molar ratio was less dark than the band produced by siRNA alone.

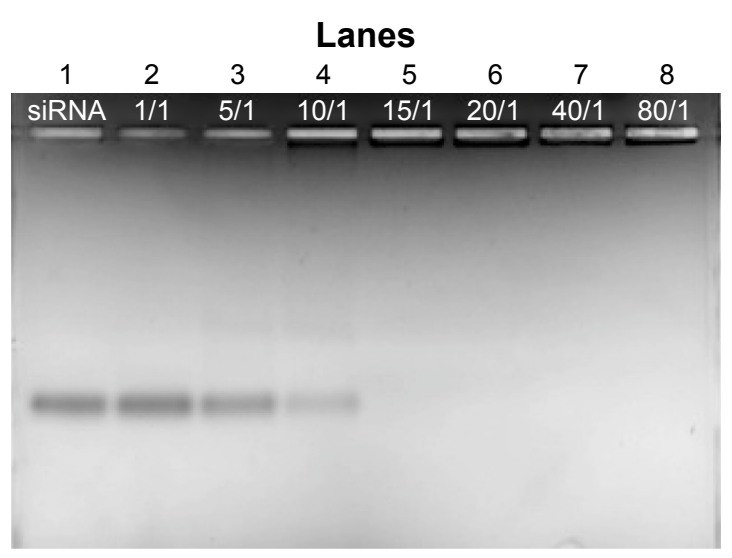

Figure 3 Binding ability of siRNA to STR-HK studied by agarose gel-shift assay. Notes: The formed STR-HK-siRNA complexes, stained with ethidium bromide, were investigated by electrophoresis on agarose gel (I.2\% wt/vol). siRNAs, targeting eGFP genes, were complexed with STR-HK at a series of molar ratios from I/I to 80/I. Lane I was siRNA control, and lanes 2-8 indicated correlated molar ratios. The amount of siRNA was $300 \mathrm{ng}$.

Abbreviation: siRNA, small interfering RNA.
At molar ratios above $15 / 1$, no free siRNA was detected on the agarose gel, indicating that siRNA molecules were completely complexed with STR-HK. This suggests that at molar ratios higher than $15 / 1$, there is sufficient STR-HK to neutralize the negative charge of siRNA and form complexes with siRNA.

To evaluate the stoichiometry between STR-HK and siRNA and the thermodynamic parameters during the condensation process, ITC was employed. As shown in Figure 4, the heat exchange during the titration of siRNA by STR-HK (in RNase-free water) was detected by the machine and output as raw data. By fitting the raw ITC data (upper panel of Figure 4) to a single-site model (lower panel of Figure 1), the thermodynamic parameters of the interaction were obtained and are listed in Table 1.

The obtained molar stoichiometry was 10 , which implied that ten moles of STR-HK could condense one mole of siRNA. This number was very close to the theoretical value of 10.5 , considering that the STR-HK peptide contains four positively charged residues (arginine and lysine), and there are 21 pairs of negatively charged nucleotides in the siRNA molecule. With an enthalpy of $-8.35 \mathrm{~kJ} / \mathrm{mol}, \Delta S$ of 78.67 $\mathrm{J} /(\mathrm{mol} \mathrm{K})$, and entropy of $-23.44 \mathrm{~kJ} / \mathrm{mol}$, the binding was predominantly entropy driven. Moreover, $\Delta G$ calculated using the equation $\Delta G=\Delta H-T \Delta S$ was equal to $-31.79 \mathrm{~kJ} / \mathrm{mol}$, which indicated that STR-HK and siRNA assembled spontaneously. ${ }^{27,28}$

The particle size and zeta potential of the complexes were measured to gain an understanding of the physicochemical properties of STR-HK-siRNA complexes. As shown in Figure 5A, overall particle sizes remained in the range of 80-160 nm. From a molar ratio $10 / 1$ to 60/1 (peptide: siRNA), particle size increased. However, at a molar ratio of 60/1, particle size slightly decreased and was similar to that of a molar ratio of 40/1. According to the graphs of size distribution by intensity (Figure 5), the possible reason for this phenomenon was that at the molar ratio of $60 / 1$, excess peptides formed smaller nanoparticles, and thus decreased the average size.

As expected, the zeta potential of complexes increased with increasing molar ratios (Figure 5B) due to the addition of excess positively charged peptides. Interestingly, at a molar ratio of 10/1, the surface charge of STR-HKsiRNA complexes was slightly negative $(-13 \mathrm{mV})$, and at a slightly higher molar ratio (15/1), it turned out to be positive $(15.2 \mathrm{mV})$. This interesting phenomenon indicated that siRNA molecules were not fully complexed at a molar ratio of 10/1 but could be so by slightly increasing the molar ratio. 
A

Time (s)

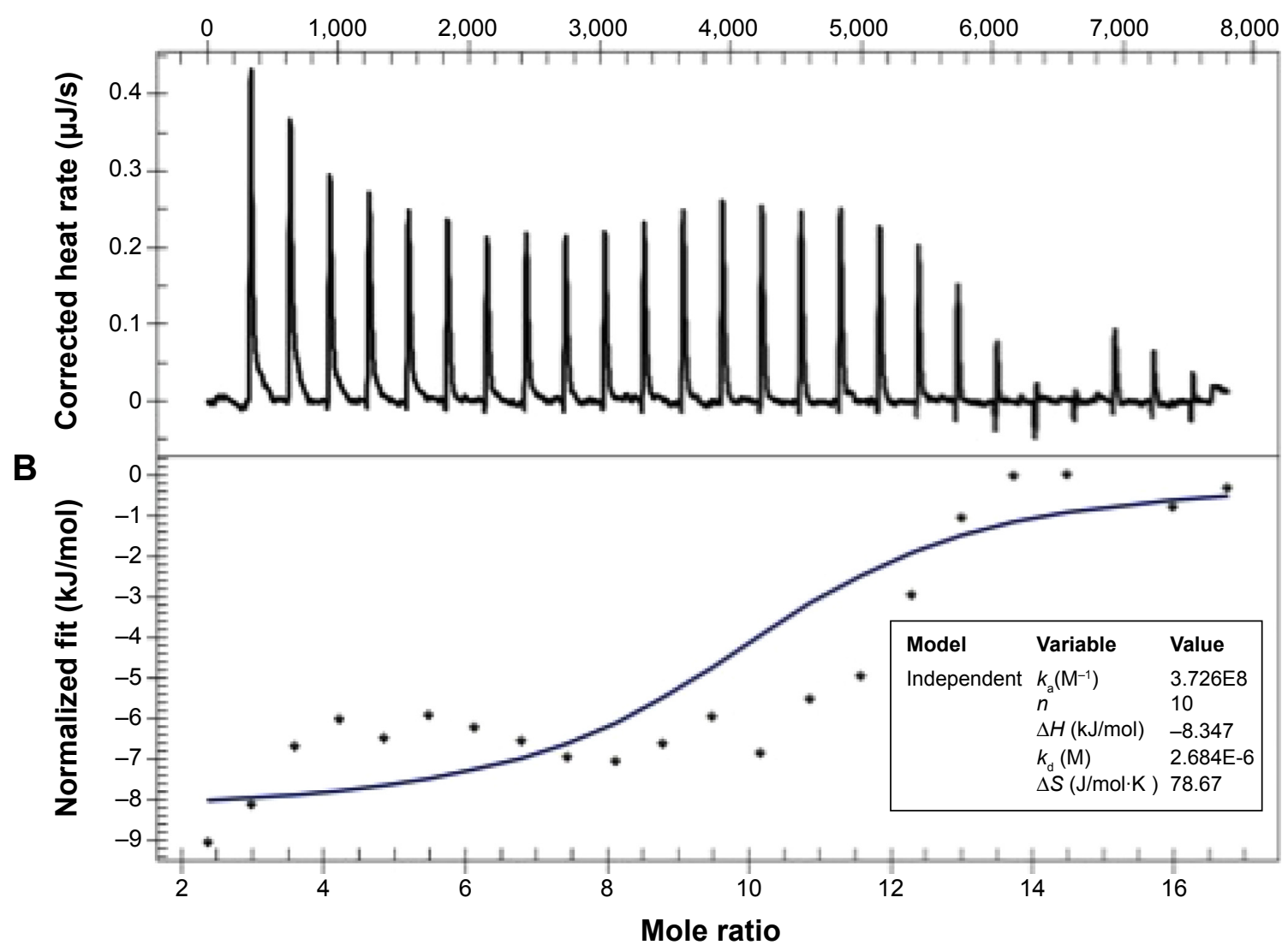

Figure 4 Calorimetric titration of siRNA with STR-HK at $25^{\circ} \mathrm{C}$ in RNase-free water at pH 6 .

Notes: (A) Corrected thermogram of calorimetric titration of siRNA with STR-HK. (B) Binding analysis of siRNA with STR-HK by fitting the raw data with an independent model. STR-HK concentration was $500 \mu \mathrm{M}$, and siRNA concentration was $10 \mu \mathrm{M}$.

Abbreviations: RNase, ribonuclease; siRNA, small interfering RNA; s, seconds.

Additionally, a SEM image of the complexes formed by STR-HK with siRNAs at a molar ratio of 20/1 is shown in Figure 6A. The graph shows that the STR-HK-siRNA complexes displayed a smooth and spherical shape with the size around $100 \mathrm{~nm}$. The morphology of the complex at a molar ratio of 20/1 was also examined by TEM, shown in Figure 6C. The electron micrograph exhibited spherical shape with the size of approximately $100 \mathrm{~nm}$. The particle size acquired from SEM and TEM experiments was consistent with the dynamic light scattering result. More importantly, this morphology indicates that STR-HK could condense siRNA to regular nanoparticles.

Furthermore, secondary structure is an important feature of peptides. From the changes of secondary structure, it can prove the interactions of STR-HK and siRNAs at a molecular level. As shown in Figure 6B, STR-HK alone in water exhibited

Table I Thermodynamic parameters when titrating siRNA with STR-HK in water

\begin{tabular}{lllll}
\hline$K_{\mathrm{a}}(\mathrm{I} / \mathrm{M})$ & $\Delta \boldsymbol{H}(\mathrm{kJ} / \mathrm{mol})$ & $\boldsymbol{n}$ & $\boldsymbol{K}_{\mathrm{d}}(\mathbf{M})$ & $\Delta \boldsymbol{S}(\mathrm{J} /[\mathrm{mol} \cdot \mathrm{K}])$ \\
\hline $3.726 \times 10^{5}$ & -8.347 & 10 & $2.684 \times 10^{-6}$ & 78.67 \\
\hline
\end{tabular}

Abbreviation: siRNA, short interfering RNA. a random coil structure with a minimum at $202 \mathrm{~nm}$. After adding siRNAs to the peptide solution to form complexes at a molar ratio of 10/1, a clear conformational change occurred and a minimum at $213 \mathrm{~nm}$ was observed, which implied a typical $\beta$ sheet structure. By adding more siRNAs to attain the molar ratio of 5/1, the absolute values of the minimum spectra at $213 \mathrm{~nm}$ and the maximum spectra at $190 \mathrm{~nm}$ were increased. The results indicated that upon interaction with siRNAs, STR-HK adopted a more ordered secondary structure of $\beta$ sheet instead of a randomly folded structure. The conformational change also revealed the flexibility of STR-HK when it formed regular nanoparticles with siRNAs.

\section{Cytotoxicity of STR-HK-siRNA complexes}

The cytotoxicity of peptide-siRNA complexes was evaluated by the CCK-8 assay, and Lipo was used as the control. As shown in Figure 7A, after 24 hours of treatment, both peptide alone and Lipo alone caused almost no cytotoxicity. The cytotoxicity of STR-HK-siRNA complexes at molar ratios from $20 / 1$ to $60 / 1$ was less than $5 \%$. However, the 
A

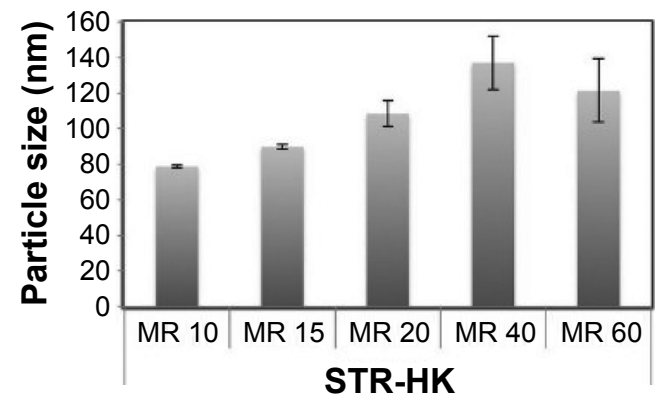

STR-HK-siRNA MR 40

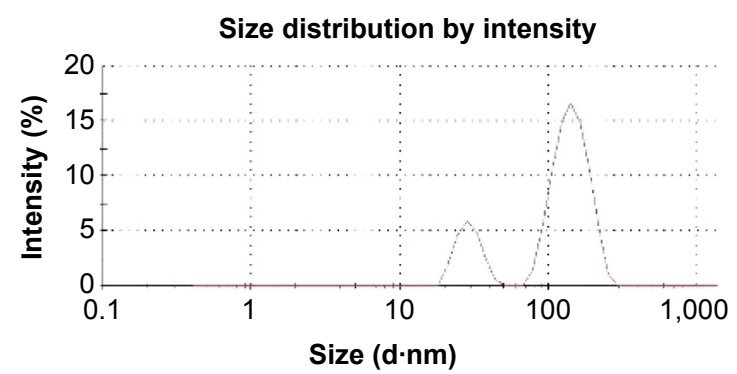

B

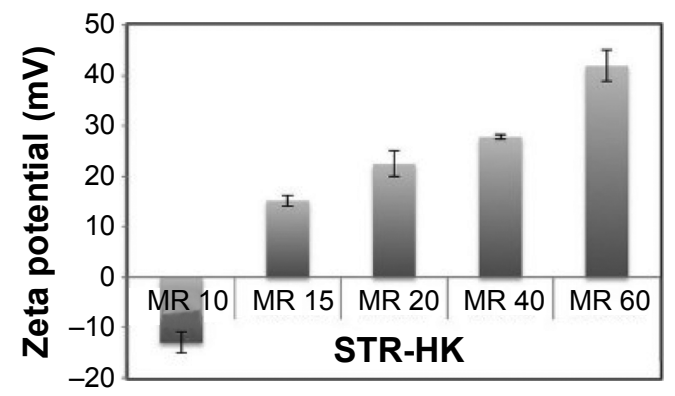

STR-HK-SIRNA MR 60

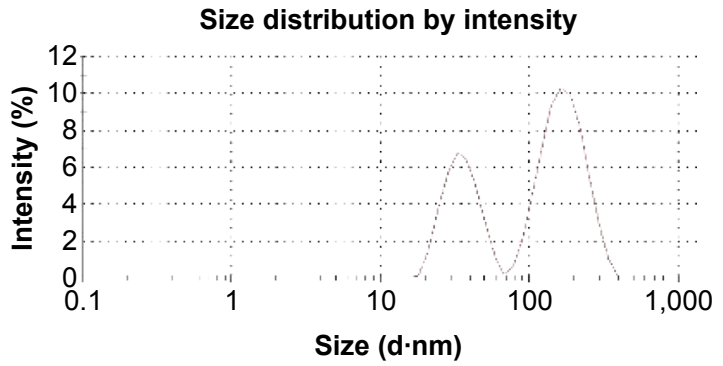

Figure 5 (A) The hydrodynamic diameter and (B) zeta potential of the STR-HK-siRNA complexes at different molar ratios were measured by DLS.

Notes: The lower two graphs are the size distribution by intensity of STR-HK-siRNA complexes at a molar ratio of 40/I and 60/I. The siRNA concentration was fixed as $100 \mathrm{nM}$. At different molar ratios, the amount of STR-HK was adjusted. Results are expressed as mean \pm standard deviation ( $\mathrm{n}=3$ ). The difference of size distribution at a molar ratio of $40 / 1$ and $60 / 1$ is not statistically significant.

Abbreviations: siRNA, small interfering RNA; DLS, dynamic light scattering; MR, peptide/siRNA molar ratio.

\section{A}

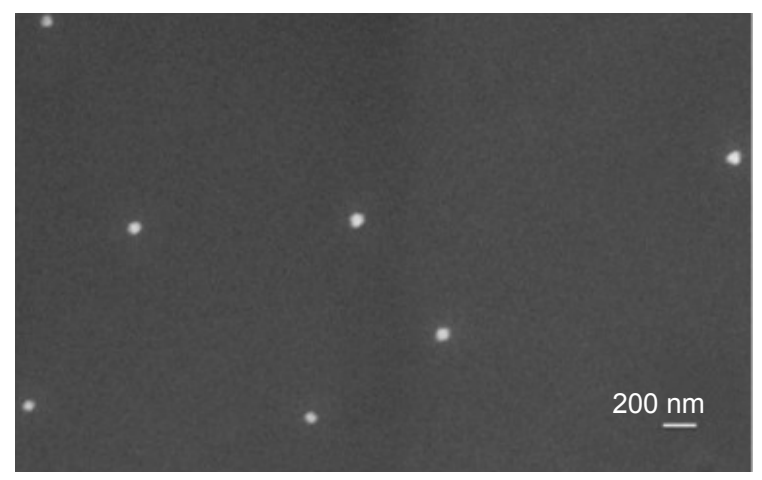

B
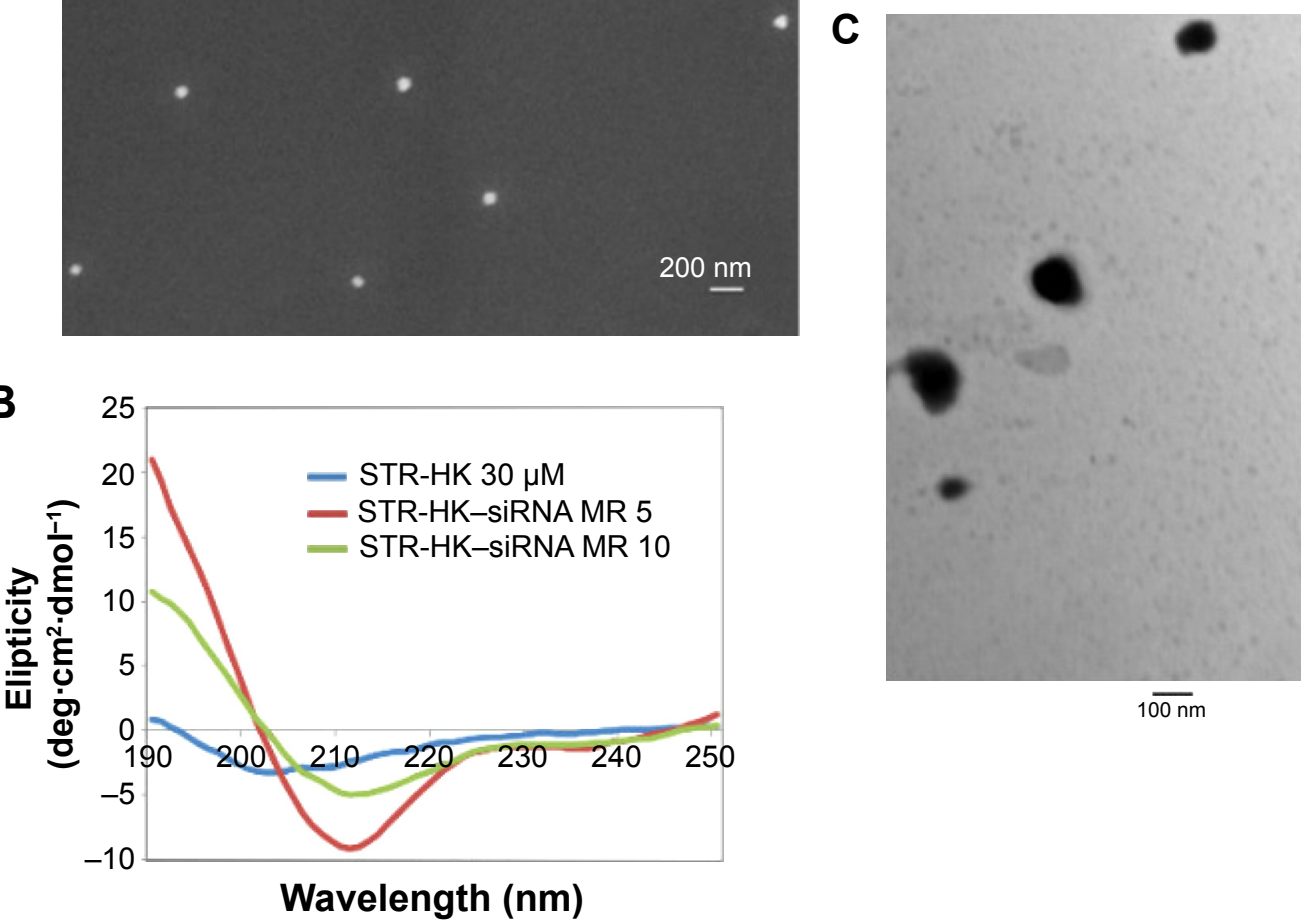

Figure 6 (A) Morphology of STR-HK-siRNA complexes at a molar ratio of 20/I, where siRNA concentration was I00 nM. (B) CD spectra of STR-HK alone and STR-HKsiRNA at different molar ratios. STR-HK concentration was fixed at $30 \mu \mathrm{M}$, and STR-HK-siRNA complexes were formulated at molar ratios of 5/I and I0/I. (C) Morphology of STR-HK-siRNA complexes at a molar ratio of 20/I with siRNA concentration of $100 \mathrm{nM}$.

Abbreviations: siRNA, small interfering RNA; CD, circular dichroism; deg, degree; MR, peptide/siRNA molar ratio. 
A

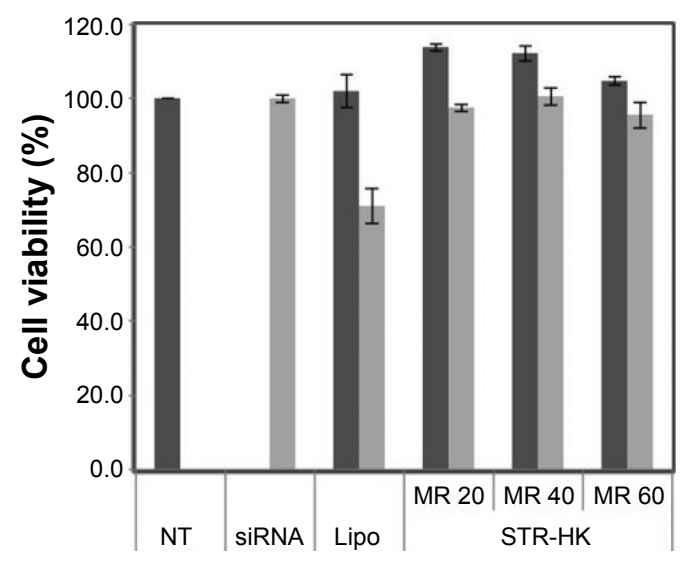

B

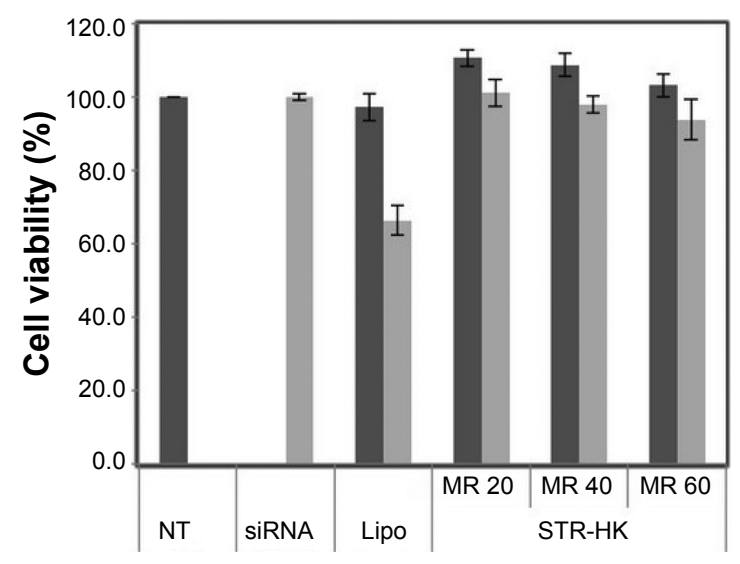

- Without siRNA - With siRNA

Figure 7 Cell viability results of PC-3 cells treated with peptide-siRNA complexes (siRNA concentration: $100 \mathrm{nM}$ ) at different molar ratios or peptide alone at the corresponding molar ratio.

Notes: (A) Cell viability after 24 hours treatment. (B) Cell viability after 48 hours treatment. Results are expressed as mean \pm standard deviation ( $\mathrm{n}=3$ ).

Abbreviations: siRNA, small interfering RNA; NT, non-treated; Lipo, Lipofectamine 2000; MR, peptide/siRNA molar ratio.

cytotoxicity of STR-HK-siRNA complexes was significantly lower than that of Lipo after 24 hours of treatment. To evaluate the long-term cytotoxicity of the complexes, cytotoxicity after 48 hours of treatment was also studied. Figure 7B shows that the cytotoxicity of each treatment followed a similar trend to that after 24 hours of treatment. These results indicated that STR-HK did not cause either short-term or long-term cytotoxicity, which was superior to Lipo in this criterion.

\section{Cellular uptake of STR-HK-siRNA complexes}

The cellular uptake of STR-HK-Cy3-labeled siRNAs complexes was studied with fluorescence microscopy and fluorescence activated cell sorting. As shown in Figure 8, most cells treated with Lipo-Cy3-labeled siRNA complexes displayed red dots in their cytosol. In the cells treated with STR-HKsiRNA complexes, siRNAs were localized to regions in close proximity to the nuclear membrane and were distributed in a non-homogeneous pattern at the periphery of the nucleus, which indicated the possibility of endocytic delivery. ${ }^{29}$ More interestingly, the cellular uptake of STR-HK-siRNA complexes was molar ratio dependent and was almost equivalent to that of the Lipo-siRNA complexes at a molar ratio of 60/1 (Figure 9). These data indicated that STR-HK could efficiently deliver sufficient Cy3-labeled siRNAs into PC-3 cells.

\section{In vitro transfection of peptide-siRNA complexes}

To evaluate the transfection efficiency of STR-HK, PC-3 cells were treated with the complexes formed by STR-HK with GAPDH siRNA at different molar ratios. As shown in Figure 10, the transfection efficiency of STR-HK increased with the increasing molar ratios and almost reached the level similar to Lipo at the molar ratio of 60/1.

\section{Discussion}

siRNA molecules hold great therapeutic potential for the development of RNA interference-based drugs to interfere with various diseases. ${ }^{19,20,30-32}$ However, siRNA therapeutics were limited by their low bioavailability due to their physicochemical properties (negative charges, large molecular weight, and size) and instability with plasma half-life of about 10 minutes, ${ }^{33-35}$ immune stimulation when administered systemically, ${ }^{36}$ and possible off-target effects due to partial nucleotide sequence match between the siRNA and off-target mRNA. ${ }^{37}$ Seeking efficient delivery systems for these molecules is a prerequisite for successful gene therapy. CPPs as one group of non-viral peptide-based delivery vectors have attracted more and more attention due to their high internalization efficiency, low cytotoxicity, and flexible structural design. ${ }^{30,38,39}$ Recently, a handful of papers have shown that stearylation is a successful strategy to enhance the transfection efficiency of CPPs mostly for DNA delivery. Several delivery systems have incorporated this strategy for siRNA delivery. ${ }^{20}$ Considering the similarities and differences between DNA/plasmid and siRNA, a novel siRNA delivery vector was constructed by the conjugation of stearic acid to the N-terminus of the sequence HHHPKPKRKV, where PKPKRKV is a cytoplasm localization sequence. Our result demonstrated that after cellular uptake, 

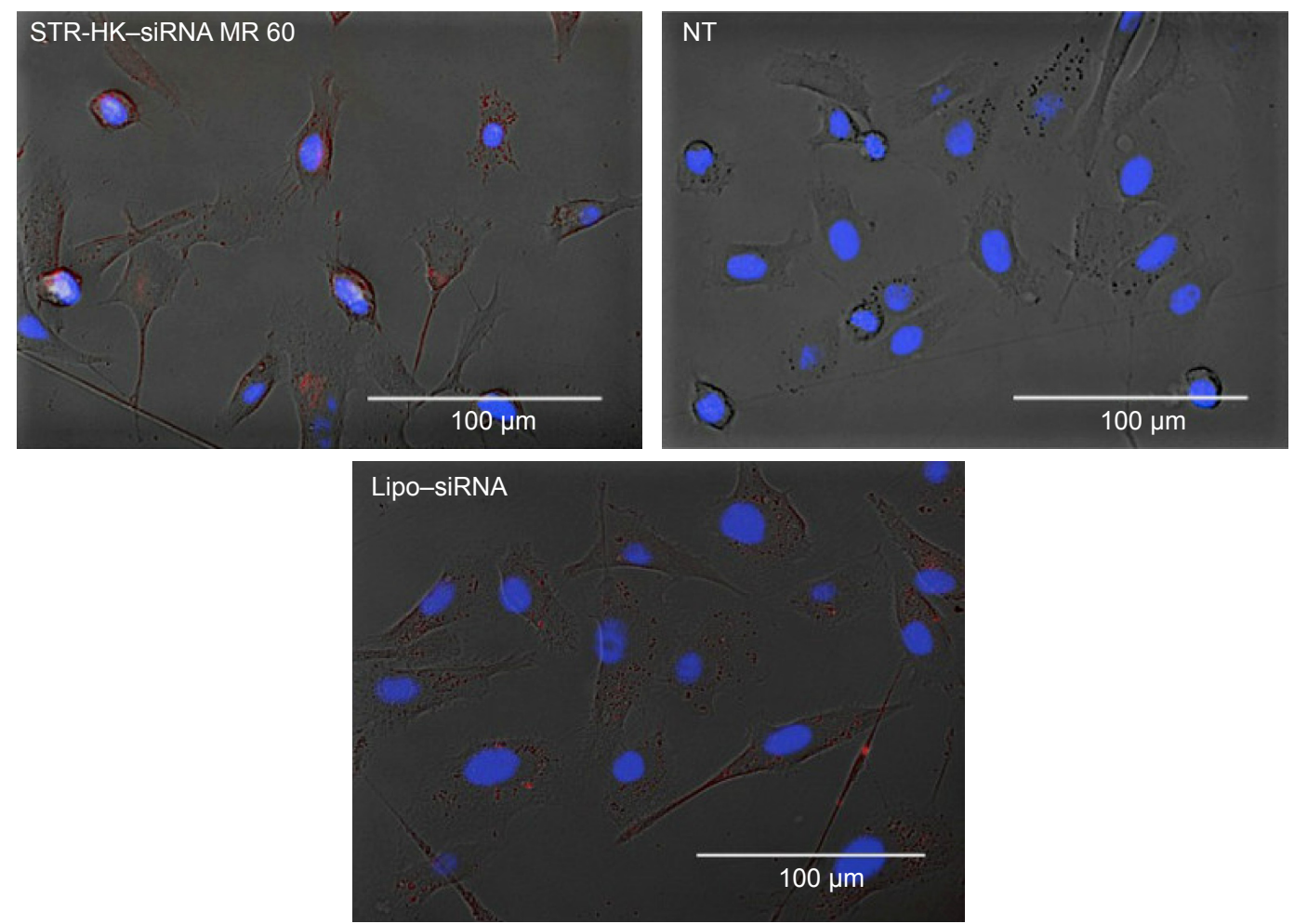

Figure 8 Fluorescence microscope image of STR-HK-siRNA complexes at molar ratio 20/I.

Notes: The red fluorescence indicated Cy3-labeled siRNA and blue fluorescence represented DAPI-stained nuclei. NT was non-treated cells, used as a negative control. Cells treated with Lipo-siRNA complexes were a positive control. The scale bar was $100 \mu \mathrm{m}$.

Abbreviations: DAPI, 4',6-diamidino-2-phenylindole; siRNA, small interfering RNA; NT, non-treated; Lipo, Lipofectamine 2000; MR, peptide/siRNA molar ratio.

the Cy3-labeled siRNAs were localized in the cytosol and distributed in a heterogeneous pattern (Figure 8), which indicated the possibility of siRNA uptake via an endocytic pathway. ${ }^{29}$

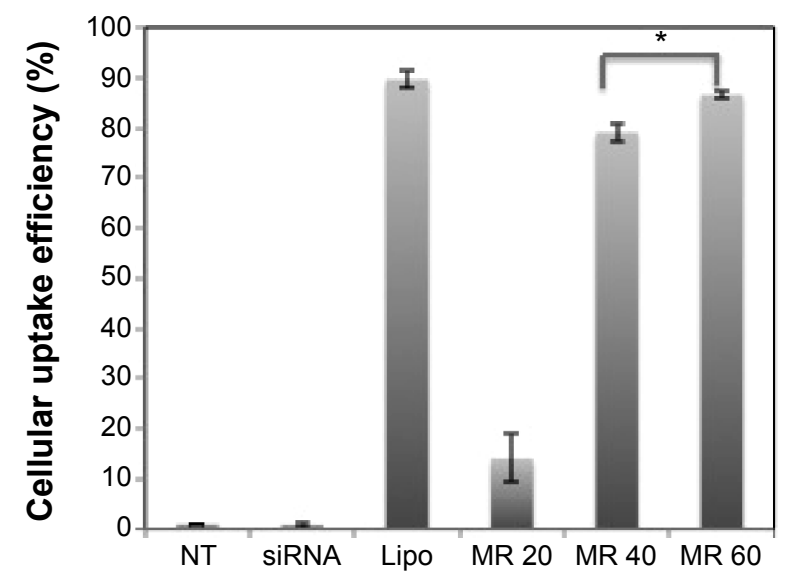

Figure 9 FACS results of cellular uptake of siRNA.

Notes: Non-treated sample was negative control; Lipo-siRNA complexes were positive control. Cy3-labeled GAPDH siRNA was used here. siRNA concentration was $100 \mathrm{nM}$ in both experiments. ${ }^{* P}$-value $<0.05$; the difference of cellular uptake efficiency of siRNA at a molar ratio of $40 / 1$ and $60 / 1$ is statistically significant. Results are expressed as mean \pm standard deviation $(n=3)$.

Abbreviations: FACS, fluorescence activated cell sorting; siRNA, small interfering RNA; Lipo, Lipofectamine 2000; GAPDH, glyceraldehyde 3-phosphate dehydrogenase; NT, non-treated; MR, peptide/siRNA molar ratio.
The formation of stable and small nanoparticles for CPP-siRNA complexes is undoubtedly an important feature to mediate high transfection efficiency. ${ }^{40}$ The result of Agarose gel-shift assay suggested that STR-HK at molar ratios above $15 / 1$ was sufficient to neutralize the negative charge of siRNA and form complexes with siRNA. The high affinity of

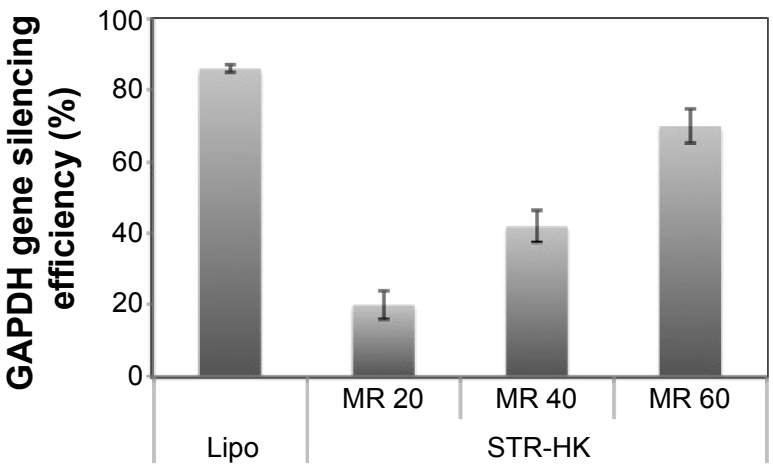

Figure 10 Gene silencing efficiency in vitro.

Notes: Silencing of GAPDH gene in PC-3 cells was evaluated by qRT-PCR. GAPDH siRNA concentration was $100 \mathrm{nM}$. Lipo was the positive control, and scrambled siRNA was used as the negative control. Results are expressed as mean \pm standard deviation $(n=3)$.

Abbreviations: GAPDH, glyceraldehyde 3-phosphate dehydrogenase; qRT-PCR, quantitative real-time polymerase chain reaction; siRNA, small interfering RNA; Lipo, Lipofectamine 2000; MR, peptide/siRNA molar ratio. 
STR-HK for siRNA $\left(K_{\mathrm{d}}: 2.68 \mathrm{E}-6 \mathrm{M}\right)$ is essentially associated with electrostatic interactions involving arginine, lysine residues, and siRNA molecules. Moreover, ITC data revealed that the interaction between STR-HK and siRNA was thermodynamically favored, and the driving forces include hydrophobic interaction among stearyl moieties and hydrogen bonding among amino acid residues when the peptide forms secondary structure of a $\beta$ sheet. The conformational change of STR-HK from random coil to the secondary structure of the $\beta$ sheet upon the formation of STR-HK-siRNA complexes indicated that STR-HK represented a more stable structure when forming complexes with siRNA than peptide alone. Moreover, the stable complexes protect siRNA molecules without affecting their silencing efficiency.

The SEM image and TEM image (Figure 6) showed that STR-HK-siRNA complexes displayed a spherical shape. Ideally, to target tumors, the diameter of CPPs-siRNA particles should not exceed $100-300 \mathrm{~nm}$ for efficient uptake. ${ }^{30}$ In this report, the particle size of STR-HK-siRNA complexes at a molar ratio of $>15 / 1$ was in the range of 100-160 $\mathrm{nm}$ and fulfilled the criteria of size required for an efficient transfection agent. At a molar ratio of 10/1, STR-HK-siRNA complexes displayed a slightly negative surface charge $(-13 \mathrm{mV})$, indicating the surface of the complex was not fully covered by positive charged peptide. At a molar ratio of $15 / 1$, the surface charge of the complex increased to $15 \mathrm{mV}$, implying that the surface of the complex was fully covered by peptide; at even a higher molar ratio, the surface charge of the complex increased to $42 \mathrm{mV}$ (at MR 60/1). The net positive surface charge could reduce the aggregation of the complexes and enhance the affinity of the complexes with the negatively charged cell membrane via electrostatic interaction, ${ }^{41}$ thus, potentially increasing the siRNA delivery efficiency. The quantified cellular uptake of Cy3-labeled siRNA showed that at a molar ratio of 20/1, the uptake of Cy3-labeled siRNA was $14 \%$; however, at a molar ratio of $40 / 1$, it increased to $79 \%$. This significant change was probably due to the increase in the net positive surface charge and the content of stearyl moiety that enhances the interaction of the complex and the lipid bilayer via hydrophobic force. In addition, at a molar ratio of $60 / 1$, the uptake efficiency increased to $87 \%$, which is similar to that of Lipo but significantly higher than that at a molar ratio of 40/1, implying that optimization of the molar ratio for siRNA delivery is crucial.

After STR-HK-siRNA complexes entered the cytoplasm, the stearyl moiety could disrupt the endosomal membrane through hydrophobic interaction with the lipid bilayer and the histidine residues could induce the proton sponge effect, leading to the rupture of the endosomal membrane to facilitate the endosomal release of siRNA. ${ }^{42}$ The results showed that the transfection efficiency was consistent with the cellular uptake efficiency at various molar ratios. At a molar ratio of 60/1,

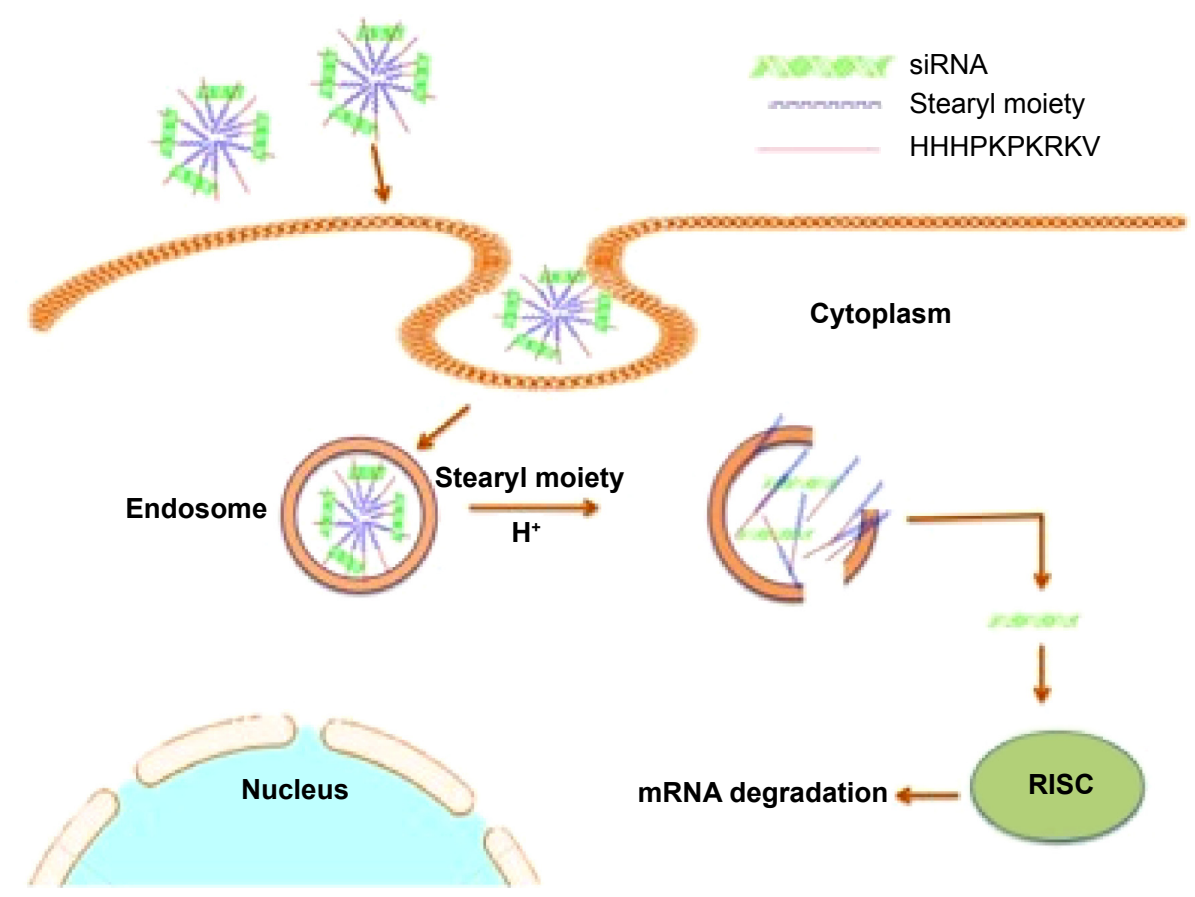

Figure I I The schematic of STR-HK-siRNA complex uptake and endosomal release. Abbreviations: siRNA, small interfering RNA; RISC, RNA-induced silencing complex; mRNA, messenger RNA. 
STR-HK achieved a similar transfection level to that obtained with Lipo. The significant difference in GAPDH transfection level at a molar ratio of $40 / 1$ and 60/1 is possibly caused by the significant difference in siRNA uptake and different amounts of stearyl moiety and histidine in the complex formulation that affected the endosome release of siRNA. Furthermore, the cytotoxicity of STR-HK was less than $5 \%$, which was significantly lower than that of Lipo. Taken together, a schematic of the uptake of STR-HK-siRNA complex and its endosomal release was proposed (Figure 11).

\section{Conclusion}

In this study, a novel siRNA delivery vector was constructed by coupling stearic acid to the N-terminus of HHHPKPKRKV. Our results demonstrated that STR-HK formed stable complexes with siRNA via non-covalent interactions and mediated efficient delivery of siRNA to PC-3 cells. These results, with the fact that STR-HK induced minimal cytotoxicity while achieving comparable gene silencing efficiency to Lipo, prove that STR-HK is a promising vector for siRNA delivery.

\section{Acknowledgments}

We are grateful for the financial support from the Canadian Foundation for Innovation, the Natural Sciences and Engineering Research Council of Canada, the Canada Research Chairs program, and the Waterloo Institute of Nanotechnology. Moreover, thanks to Dr Xiaoxia Han for proofreading this manuscript.

\section{Disclosure}

The authors report no conflicts of interest in this work.

\section{References}

1. McManus MT, Sharp PA. Gene silencing in mammals by small interfering RNAs. Nat Rev Genet. 2002;3:737-747.

2. Hannon GJ, Rossi JJ. Unlocking the potential of the human genome with RNA interference. Nature. 2004;431:371-378.

3. Caplen NJ, Parrish S, Imani F, Fire A, Morgan RA. Specific inhibition of gene expression by small double-stranded RNAs in invertebrate and vertebrate systems. Proc Natl Acad Sci U S A. 2001;98:9742-9747.

4. Verma UN, Surabhi RM, Schmaltieg A, Becerra C, Gaynor RB. Small interfering RNAs directed against $\beta$-Catenin inhibit the in vitro and in vivo growth of colon cancer cells. J Clin Cancer Res. 2003;9:1291-1300.

5. Soutschek J, Akinc A, Bramlage B, et al. Therapeutic silencing of an endogenous gene by systemic administration of modified siRNAs. Nature. 2004;432:173-178.

6. Oliveira S, Storm G, Schiffelers RM. Targeted delivery of siRNA. J Biomed Biotechnol. 2006;4:1-9.

7. Mok H, Park TG. Self-crosslinked and reducible fusogenic peptides for intracellular delivery of siRNA. Biopolymers. 2008;89:881-888.

8. Kim SH, Mok H, Jeong JH, Kim SW, Park TG. Comparative evaluation of target-specific GFP gene silencing efficiencies for antisense ODN, synthetic siRNA, and siRNA plasmid complexed with PEI-PEG-FOL conjugate. Bioconjug Chem. 2006;17:241-244.
9. Urban-Klein B, Werth S, Abuharbeid S, Czubayko F, Aigner A. RNAi-mediated gene-targeting through systemic application of polyethylenimine (PEI)-complexed siRNA in vivo. Gene Ther. 2005;12: 461-466.

10. Landen CN Jr, Chavez-Reyes A, Bucana C, et al. Therapeutic EphA2 gene targeting in vivo using neutral liposomal small interfering RNA delivery. Cancer Res. 2005;65:6910-6918.

11. Zimmermann TS, Lee AC, Akinc A, et al. RNAi-mediated gene silencing in non-human primates. Nature. 2006;441:111-114.

12. Santel A, Aleku M, Keil O, et al. RNA interference in the mouse vascular endothelium by systemic administration of siRNA-lipoplexes for cancer therapy. Gene Ther. 2006;13:1360-1370.

13. Yano J, Hirabayashi K, Nakagawa S, et al. Antitumor activity of small interfering RNA/cationic liposome complex in mouse models of cancer. Clin Cancer Res. 2004;10:7721-7726.

14. Grimm D, Streetz KL, Jopling CL, et al. Fatality in mice due to oversaturation of cellular microRNA/short hairpin RNA pathways. Nature. 2006;441:537-541.

15. Jeong JH, Kim SW, Park TG. Molecular design of functional polymers for gene therapy. Prog Polym Sci. 2007;32:1239-1274.

16. Dorsett Y, Tuschl T. siRNAs: applications in functional genomics and potential as therapeutics. Nat Rev Drug Discov. 2004;3:318-329.

17. Morris MC, Vidal P, Chaloin L, Heitz F, Divita G. A new peptide vector for efficient delivery of oligonucleotides into mammalian cells. Nucleic Acids Res. 1997;25:2730-2736.

18. Simeoni F. Insight into the mechanism of the peptide-based gene delivery system MPG: implications for delivery of siRNA into mammalian cells. Nucleic Acids Res. 2003;31:2717-2724.

19. Futaki S, Ohashi W, Suzuki T, et al. Stearylated arginine-rich peptides: a new class of transfection systems. Bioconjug Chem. 2001;12: 1005-1011.

20. Tönges L, Lingor P, Egle R, Dietz GP, Fahr A. Stearylated octaarginine and artificial virus-like particles for transfection of siRNA into primary rat neurons. RNA. 2006;12:1431-1438.

21. Mäe M, El Andaloussi S, Lundin P, et al. A stearylated CPP for delivery of splice correcting oligonucleotides using a non-covalent co-incubation strategy. J Control Release. 2009;134:221-227.

22. El-Sayed A, Masuda T, Khalil I, Akita H, Harashima H. Enhanced gene expression by a novel stearylated INF7 peptide derivative through fusion independent endosomal escape. J Control Release. 2009;138:160-167.

23. Lehto T, Abes R, Oskolkov N, et al. Delivery of nucleic acids with a stearylated (RxR)4 peptide using a non-covalent co-incubation strategy. J Control Release. 2010;141:42-51.

24. Wang HY, Chen JX, Sun YX, et al. Construction of cell penetrating peptide vectors with $\mathrm{N}$-terminal stearylated nuclear localization signal for targeted delivery of DNA into the cell nuclei. J Control Release. 2011;155:26-33

25. Veiman KL, Mäger I, Ezzat K, et al. PepFect14 peptide vector for efficient gene delivery in cell cultures. Mol Pharm. 2013;10:199-210.

26. Alshamsan A, Haddadi A, Incani V, Samuel J, Lavasanifar A, Uludag H. Formulation and delivery of siRNA by oleic acid and stearic acid modified polyethylenimine. Mol Pharm. 2008;6:121-133.

27. Ladbury JE, Chowdhry BZ. Sensing the heat: the application of isothermal titration calorimetry to thermodynamic studies of biomolecular interactions. Chem Biol. 1996;3:791-801.

28. Pierce MM, Raman CS, Nall BT. Isothermal titration calorimetry of protein-protein interactions. Methods. 1999;19:213-221.

29. Veldhoen S, Laufer SD, Trampe A, Restle T. Cellular delivery of small interfering RNA by a non-covalently attached cell-penetrating peptide: quantitative analysis of uptake and biological effect. Nucleic Acids Res. 2006;34:6561-6573.

30. Hoyer JAN, Neundorf I. Peptide vectors for the nonviral delivery of nucleic acids. Acc Chem Res. 2012;45:1048-1056.

31. Meyer MA. Malignant gliomas in adults. $N$ Engl J Med. 2008;359: 494-507.

32. Pulkkanen KJ, Yla-Herttuala S. Gene therapy for malignant glioma: current clinical status. Mol Ther. 2005;12:585-598. 
33. Grimm D. Small silencing RNAs: state-of-the-art. Adv Drug Deliv Rev. 2009;61:672-703.

34. Takahashi Y, Nishikawa M, Takakura Y. Nonviral vector-mediated RNA interference: its gene silencing characteristics and important factors to achieve RNAi-based gene therapy. Adv Drug Deliv Rev. 2009;61: $760-766$.

35. Whitehead KA, Langer R, Anderson DG. Knocking down barriers: advances in siRNA delivery. Pharm Res. 2009;26:129-138.

36. Judge AD, Bola G, Lee AC, MacLachlan I. Design of noninflammatory synthetic siRNA mediating potent gene silencing in vivo. Mol Ther. 2006; 13:494-505.

37. Jackson AL, Burchard J, Schelter J, et al. Widespread siRNA off-target transcript silencing mediated by seed region sequence complementarity. RNA. 2006;12:1179-1187.

38. Bolhassani A. Potential efficacy of cell-penetrating peptides for nucleic acid and drug delivery in cancer. Biochim Biophys Acta. 2011;1816: 232-246.
39. Nakase I, Akita H, Kogure K, et al. Efficient intracellular delivery of nucleic acid pharmaceuticals using cell-penetrating peptides. Acc Chem Res. 2012;45:1132-1139.

40. Nyunt MT, Dicus CW, Cui YY, et al. Physico-chemical characterization of polylipid nanoparticles for gene delivery to the liver. Bioconjug Chem. 2009;20:2047-2054.

41. Jafari M, Xu W, Naahidi S, Chen B, Chen P. A new amphipathic, amino-acid-pairing (AAP) peptide as siRNA delivery carrier: physicochemical characterization and in vitro uptake. J Phys Chem B. 2012;116: 13183-13191.

42. Jenssen H, Hamill P, Hancock RE. Peptide antimicrobial agents. Clin Microbiol Rev. 2006;19:491-511.
International Journal of Nanomedicine

\section{Publish your work in this journal}

The International Journal of Nanomedicine is an international, peerreviewed journal focusing on the application of nanotechnology in diagnostics, therapeutics, and drug delivery systems throughout the biomedical field. This journal is indexed on PubMed Central, MedLine, CAS, SciSearch ${ }^{\circledR}$, Current Contents ${ }^{\circledR} /$ Clinical Medicine,

\section{Dovepress}

Journal Citation Reports/Science Edition, EMBase, Scopus and the Elsevier Bibliographic databases. The manuscript management system is completely online and includes a very quick and fair peer-review system, which is all easy to use. Visit http://www.dovepress.com/ testimonials.php to read real quotes from published authors. 